\title{
FIRE SAFETY OF MASS TIMBER BUILDINGS WITH CLT IN USA
}

\author{
David Barber* \\ Principal \\ Arup \\ 1120 Connecticut Avenue \\ Washington, DC 20036 \\ E-mail: david.barber@arup.com \\ (Received September 2017)
}

\begin{abstract}
Multistory buildings using mass timber and cross-laminated timber (CLT) as the primary structural elements are being planned and constructed globally, with interest starting to gather momentum in the United States. Model building codes in the United States limit timber construction to a building height of $85 \mathrm{ft}(25.9 \mathrm{~m})$ because of concerns over fire safety and structural performance. Up to $85 \mathrm{ft}$, the mass timber can be exposed. Architects and developers in the United States are pushing boundaries, requesting mass timber structures are constructed as high-rises and that load-bearing mass timber such as CLT be exposed and not fully protected. This provides an opportunity for the application of recent fire research and fire testing on exposed CLT to be applied, and existing methods of analyzing the impact of fire on engineered timber structures to be developed further. Fire testing has shown that exposing large areas of CLT significantly impacts the heat release rate and fire duration. This article provides an overview of the code requirements for timber construction in the United States, provides methods for building approval for a high-rise timber structure, and summarizes recent CLT compartment fire testing that is informing the fire engineering process. Methods for solutions are also discussed.
\end{abstract}

Keywords: Mass timber, cross-laminated timber, fire safety, fire testing, performance-based design.

\section{INTRODUCTION}

Multistory buildings using mass timber for the primary structural elements are being planned and constructed within the United States. This is due to the need for green and sustainable architecture and to use the efficiencies in construction that mass timber can bring. Cross-laminated timber (CLT) is being used for walls and floors, often combined with glulam as the gravity structural frame.

With the resurgence of mass timber as a construction material in the United States, there is also significant interest in high-rise buildings. A high-rise building with a combustible structural frame introduces a number of fire safety issues, and the extent of fire hazard posed by any exposed mass timber needs to be addressed.

\section{CODE COMPLIANCE}

Each State within the United States adopts one or more model building codes. All 50 states adopt the International Code Council's (ICC)

\footnotetext{
* Corresponding author
}

International Building Code (IBC) (ICC 2015), with some states also adopting NFPA 101 "Life Safety Code" (NFPA 2015). Each State adapts and amends the model codes to provide the basis for construction compliance. The adoption process may take a number of years. Some cities have their own building code, such as New York City (City of New York 2014). Also required to be met are other relevant codes and standards that will also impact on aspects of construction, fire protection system design, maintenance and firefighting operations, including the International Fire Code and numerous referenced standards.

The IBC has fire protection requirements that provide for occupant life safety in fire, access and equipment for firefighters, and prevent fire spread to neighboring buildings. Protection of the building structure from fire varies with height area.

\section{Type of Construction, Height, and Building Area}

Timber construction is referred to as combustible construction in the IBC. Concrete and steel 
construction is referred to as noncombustible construction. Within the IBC, timber construction can be used within Types III, IV and V construction. Types III, IV, V are limited to low- and medium-rise buildings, with limited building area:

- Type III allows combustible construction for internal load-bearing and non-load-bearing elements. Exterior wall assembles may be fire-retarded timber, provided they meet a 2-h fire resistance rating (FRR), otherwise external walls must be noncombustible.

- Type IV (Heavy timber) is a method of construction based on timber members having minimum dimensions, which provides an inherent FRR. Type IV construction also permits exterior wall assembles to be fire-retarded timber, provided they meet a 2-h FRR, otherwise they must be noncombustible.

- Type V construction permits any materials used by the Code and also permits wall assemblies to be combustible but is limited to buildings of four floors or less, with very restrictive floor area.

The IBC states limitations on building floor area, number of stories and overall height, based on differing types of construction, the occupancy use, fire protection systems installed, and the FRRs to be achieved. For low-rise buildings (up to four floors), the use of timber for residential buildings is fairly unrestricted. Above $85 \mathrm{ft}(25.9 \mathrm{~m})$ building height (to the roof), timber is not permitted. Guidance documents on the height and areas permitted in the IBC for timber construction is freely available from the AWC website (AWC 2012).

The IBC requires buildings with an occupied floor above $75 \mathrm{ft}(22.9 \mathrm{~m})$ (defined as high rise) to have an increased level of fire protection and structural performance, with noncombustible construction used for the primary structural elements. Construction Types I and II are used for high-rise construction.

\section{IBC-CLT Compliance}

The 2015 IBC has been updated to recognize CLT for use. A building constructed with the primary structural elements (columns, beams, floors, and load-bearing walls) of CLT can meet Construction Type III, IV, or Type V. The 2015 IBC is progressively being adopted across the United States. The use of CLT as a building material, even for low- and mid-rise construction, is not always straight forward and in states or cities that have not adopted the 2015 IBC, a performance-based application is required for the use of CLT.

\section{Building Fire Resistance}

The FRR test is the basis of approving building elements for use in construction. A structural element that is to achieve an FRR is required to meet ASTM E119 (ASTM 2016) or UL 263 (UL 2014).

Low-rise buildings of up to three stories can have zero fire rating for the structure and may suffer significant damage in a fire. Buildings are permitted to be larger or taller if they include firerated structure, fire-separated compartments; are separated from neighbors; or automatic sprinkler protection is installed. Medium-rise buildings, with a height to the roof of less than $85 \mathrm{ft}$, are required to have a 1-h FRR and are limited in area. With sprinkler protection or separation by fire walls, larger floor areas are permitted. Highrise buildings ( $75 \mathrm{ft}$ or more to the highest occupied floor) are required to have an FRR of $2 \mathrm{~h}$ to the primary structure, sprinkler protection, and many additional fire protection features. For buildings taller than $420 \mathrm{ft}$, fire ratings are $3 \mathrm{~h}$ for the primary structure and $2 \mathrm{~h}$ for floors.

High-rise construction is represented by construction types IA and IB, which require a noncombustible primary structure. For buildings of 12 floors or less, the FRR for the structure can be reduced to $1 \mathrm{~h}$, provided additional reliability enhancements are made to the sprinkler protection and occupant alerting. The reduction from 2 to $1 \mathrm{~h}$ is recognition that evacuation can occur relatively quickly and fire department intervention external to the building can still occur with a degree of success, even in the highly unlikely situation of sprinkler failure. 
Buildings higher 12 floors are required to have a minimum of 2-h FRR to all primary structural elements and floors, with columns being $3 \mathrm{~h}$. The higher fire ratings are required to support the longer evacuation time for occupants and fire department intervention via the fire-protected stairwells and fire service access elevators (required once a building is $120 \mathrm{ft}$ ).

For a high-rise building, the primary structure must continue to support applied loads even in the highly unlikely case of the sprinklers failing and the fire department intervention being delayed. The approach of providing high-rise structural fire ratings based on resisting a "fully developed fire," being a fire that burns until decay, has been part of US code development for decades (Department of Commerce 1942). This approach to high-rise construction differs from some countries, where a highrise building may not be required to withstand a fully developed fire. Hence, there is a significant difference in expected structural performance in fire for a high-rise building, when compared with a medium- or low-rise building, within the IBC.

\section{Mass Timber FRR}

Mass timber building elements have fire resistant properties that have been very well researched and understood, with significant standardized fire testing undertaken in North America (White 2016). Buildings that use engineered mass timber products can achieve the IBC-required FRRs of $2 \mathrm{~h}$, without relying on additional passive fire protection such as fire-rated gypsum plasterboard. Methods for calculating the FRR are provided within the National Design Specification for Wood Construction (AWC 2015a), as referenced by the IBC, with further detail provided by AWC's "Calculating the Fire Resistance of Exposed Wood Members" (AWC 2015b). Both these guides include a calculation method for determining the FRR for CLT.

\section{Combustible Interior Finishes}

The IBC permits limited combustibility interior finishes within all buildings. Flammability of all interior finish materials is required to be proven through fire testing to ASTM E84 (ASTM 2015). The IBC permits timber as an interior finish within most occupancy types, provided it meets with a Class C rating, when tested to ASTM E84, with sprinkler protection installed (Class $\mathrm{C}$ is the least restrictive). Both CLT and glulam can be used as an interior finish given they will meet Class B or Class C, when tested to meet ASTM E84.

\section{FIRE TESTING DOCUMENTATION TO SUPPORT THE USE OF CLT}

Building permits are primarily based on evidential fire testing for interior finishes, exterior walls, and the primary structure. An issue for mass timber buildings in the United States is the lack of substantive fire testing of CLT products, where those tests are carried out in the United States to meet the IBC. Fire testing carried out at non-US facilities is typically not accepted by building approval authorities (referred to as the Authority Having Jurisdiction, AHJ). The lack of evidential fire testing for CLT products has resulted in slow or no building approval as all components need to have the required proof of FRR when the design is submitted.

In the last $2 \mathrm{yr}$, North American CLT suppliers have realized that fire testing is required to allow their products to have an easier path for building approval and a number of fire tests have been undertaken. CLT suppliers have completed fire tests for floors and walls, meeting ASTM E119, with those fire tests carried out in US-based test facilities. Fire tests have also been carried out on CLT floors with the underside exposed, as desired by architects. These fire tests have also been carried out to $2 \mathrm{~h}$, as required by the IBC for highrise buildings. Panel-to-panel connections have also been tested for floors or walls. There are still gaps in the current testing documentation for intersections between CLT walls and floors, and there are few fire-tested penetration seals, for cables, pipes, and ducts within CLT floors or walls. These gaps in construction data will continue to be filled as demand for the CLT use grows. 
It is expected that as AHs become more familiar with CLT, that calculation methods for an FRR, as documented within the CLT Handbook (Karacabeyli and Douglas 2013) will become more acceptable for building permit applications. The CLT Handbook is becoming more widely accepted as a design guide, and the analysis correlations for an FRR can assist and inform an AHJ of the expected CLT thickness.

\section{HIGH-RISE TIMBER BUILDING-PATH TO PERMIT}

High-rise construction is represented by types IA and IB that require noncombustible construction for the primary structure. Approval for a high-rise timber structure requires the proposal of an alternative engineering design, which may be permitted by the "alternative materials, design and methods of construction, and equipment" section of the IBC.

Undertaking an alternative engineering approach (or a performance-based design) is subject to approval by the AHJ. The methodology for developing an alternative engineering design varies among states in the United States and can also vary within the state. The process of approval is typically based on proving that the high-rise timber building will provide a level of fire safety that is equivalent in performance to a codecompliant building of the same height, area, and use. A high-rise timber building is a very new form of construction and hence will undergo intense approval scrutiny as it progresses through approvals. The alternative engineering documentation will need to be supported by detailed information on fire testing for the mass timber components and assemblies, with analysis and drawings, to prove that using mass timber as the primary structure provides an equivalent level of safety to a noncombustible structure.

To assist with building approvals and to provide current and future high-rise buildings with useable mass timber and CLT solutions, the US Department of Agriculture has launched a Tall Wood Building Competition, which includes funding for a number of fire tests (USDA 2015). These fire tests will be carried out to meet the IBC for high-rise construction and include CLT walls and floors, CLT floor assemblies, and a number of connections. These tests will provide new information to the timber construction industry, once completed as they will be publicly available.

\section{FIRE SAFETY OF EXPOSED CLT STRUCTURES}

\section{Low- and Medium-rise Buildings}

Within the United States, buildings up to $85 \mathrm{ft}$ are permitted by the IBC to have all the load-bearing timber structure fully exposed (see Fig 1). Thus, CLT used for floors or walls can be exposed where the local jurisdiction adopts the 2015 IBC, and the building meets the height and area limitations of the code and the detailed requirements of Type IV construction. A Type IV building of up to $85 \mathrm{ft}$ will include automatic fire detection, sprinkler protection, and two fire-protected egress stairs. It will also have the first floor constructed from concrete construction, meeting Type IA (3 h fire ratings).

\section{High-Rise Buildings with Exposed Mass Timber-Issues To Be Addressed}

If a high-rise building is permitted to be constructed with mass timber as part of an alternative engineering solution, then exposing the CLT may be part of the discussion. Architects, developers, and building owners are requesting the CLT be partly exposed and not hidden behind a protective

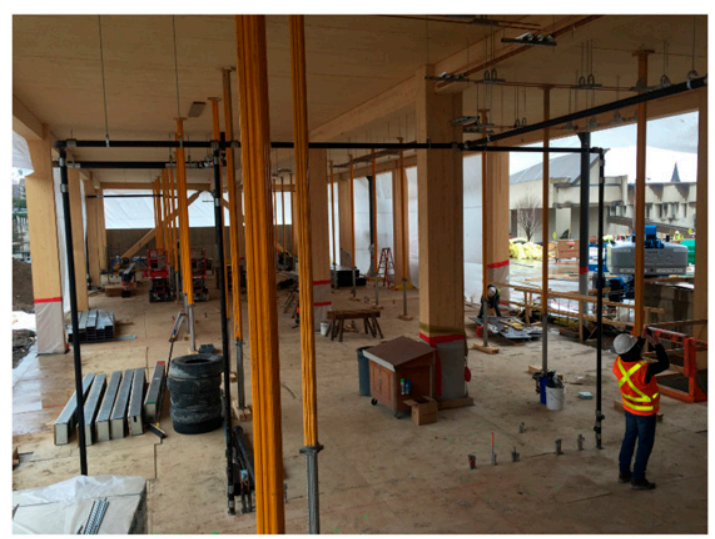

Figure 1. Type IV building under construction, using crosslaminated timber as part of the primary structure (image, Arup). 
noncombustible covering, such as fire-rated gypsum plasterboard (gypsum drywall). There is concern and debate in the design and approval community as to whether exposing mass timber and especially CLT, which forms part of the building structure is an excessive fire hazard and, therefore, should be fully protected by noncombustible protection.

Within the United States, a high-rise building that is constructed with exposed CLT will need to resist a fully developed fire, in the highly unlikely scenario where the sprinklers have failed and the fire department has limited intervention. If too much timber is exposed, then the total combustible fuel within the space (furniture, fixtures and exposed timber) can result in a fire that releases more energy than the primary structure can resist, resulting in localized structural failure. Accounting for areas of exposed CLT (not protected by a noncombustible covering) is a significant technical challenge to analyze and one that differs from a building with a noncombustible structure.

\section{Load-Bearing Elements Forming Part of the Fuel}

The key aspect to be addressed is where a building has exposed primary structure of mass timber, such as CLT, and if a fire can become fully developed, then these load-bearing building elements will form part of the combustible fuel, contributing to the fire development. To provide an FRR for timber load-bearing members, the reduced cross-section method is followed and the member size is increased, based on a constant char rate (AWC 2015a). But increasing the sectional area also introduces more combustible fuel to the room. Therefore, the FRR to be provided for the exposed load-bearing timber structure needs to be determined to include the fire load introduced by the structure itself.

\section{Influence on the Compartment Fire}

The exposed timber will also impact on the fire dynamics. In the very rare event of a fully developed fire, the fire growth rate, heat release rate (HRR), and fire duration will be influenced by the exposed timber. Fire testing (see the following section) has shown that exposed timber increases the fully developed fire peak HRR and lengthens the fire duration, because of the added combustible fuel, when compared with a compartment without any exposed timber. The issue to be addressed by the fire engineer is the total energy released from the fully developed fire, which is influenced by the area of exposed timber and the compartment ventilation.

\section{Basis of Mass Timber Protection}

To limit the area of exposed mass timber, noncombustible coverings, such as fire-rated gypsum plasterboard, calcium-silicate board, or noncombustible fiber-based batts can be used. For noncombustible structures, FRRs can be achieved by applying products such as fire-rated plasterboard to the primary structure.

For mass timber buildings, the noncombustible protection to the mass timber is required to stay in place for the duration of the expected fire, through to decay, to prevent the mass timber-forming part of the compartment fuel. For example, a CLT floor may have an inherent FRR due to its thickness of $200 \mathrm{~mm}$ to meet a 120-min FRR, but may be required to be protected with multiple layers of fire-rated plasterboard, so that the CLT is not exposed to a fire, until the fire decays to extinguishment. The noncombustible protection to the mass timber needs to be specified to achieve this goal.

\section{FIRE TESTING OF EXPOSED MASS TIMBER}

\section{Introduction}

There has been a number of full-size fire tests of rooms with exposed CLT panels (walls or underside of floor) in Canada, Europe, UK (see Fig 2), Australia, and United States (Frangi et al 2008; Wilinder 2010; Craft et al 2011; Aguanno 2013; McGregor 2013; Medina 2014; Hox et al 2015; Kimball et al 2017; Emberley et al 2017; Hadden et al 2017). The aim of the fire testing has 
been to understand how exposed timber influences fire size and duration and to also understand the effectiveness of CLT protection systems. Small-scale tests by Crielaard have also been informative (Crielaard 2015).

\section{Reaction of CLT to Fire}

The fire testing has also shown the impact of CLT that is susceptible to premature failure of the plies at the adhesive interface, before complete charring through the adhesive line occurs. This has been referred to as delamination, char fall off, de-bonding, or stickability (Klippel et al 2016). The term delamination will be used in this document. Delamination is the process in CLT where small pieces of mostly charred CLT separate from the unburnt CLT base as the charring reaches the ply interface. The separation of the

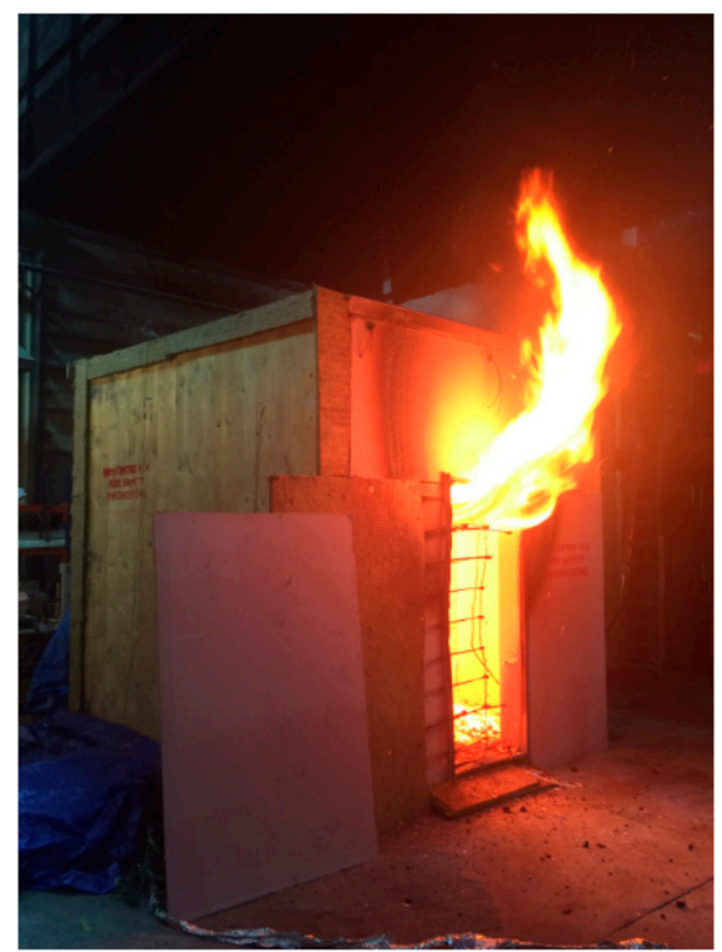

Figure 2. Exposed cross-laminated timber compartment fire test undertaken at BRE by the University of Edinburgh and Arup (image, Arup). char occurs because of the ply adhesive softening under increased temperatures (see Fig 3).

Delamination is an important issue for exposed CLT, because if the char that protects the unburnt timber falls off, unburnt timber is progressively exposed to the fire. This results in an increased burning rate at the freshly exposed timber, until a new layer of char has formed. When delamination in the CLT occurs, it can result in a higher HRR and more CLT being consumed by the fire. Delamination is typically represented in compartment fires by regrowth of the HRR as the ply interface is reached (Frangi et al 2008; McGregor 2013; Medina 2014; Klippel et al 2016). CLT panels located horizontally (underside of floors) are more susceptible to delamination than panels located vertically (walls). The extent of delamination varies between panel manufacturers, given each manufacturer uses different timber species (density), timber size, gluing patterns, and importantly, type of adhesive. Delamination is accounted for within the methodology to calculate char rate in panels within the CLT Handbook (Karacabeyli and Douglas 2013).

\section{Fire Protection Research Foundation (FPRF) Tests}

The FPRF has recently completed six full-scale fire tests on a CLT compartment, completed at National Institute of Standards and Technology (NIST), Gaithersburg, MD. The tests were finished in April 2017 and, hence, the information described in the following paragraphs is based on the author's observations and preliminary test data (Kimball et al 2017), as no formal report has been published to date.

The basis of the FPRF fire tests was to ascertain the impact on HRR and fire duration of exposed CLT within a high-rise building, based on the highly unlikely design scenario of sprinkler protection failing and no Fire Department intervention. This is a required scenario to ascertain the structural robustness of the construction material. 


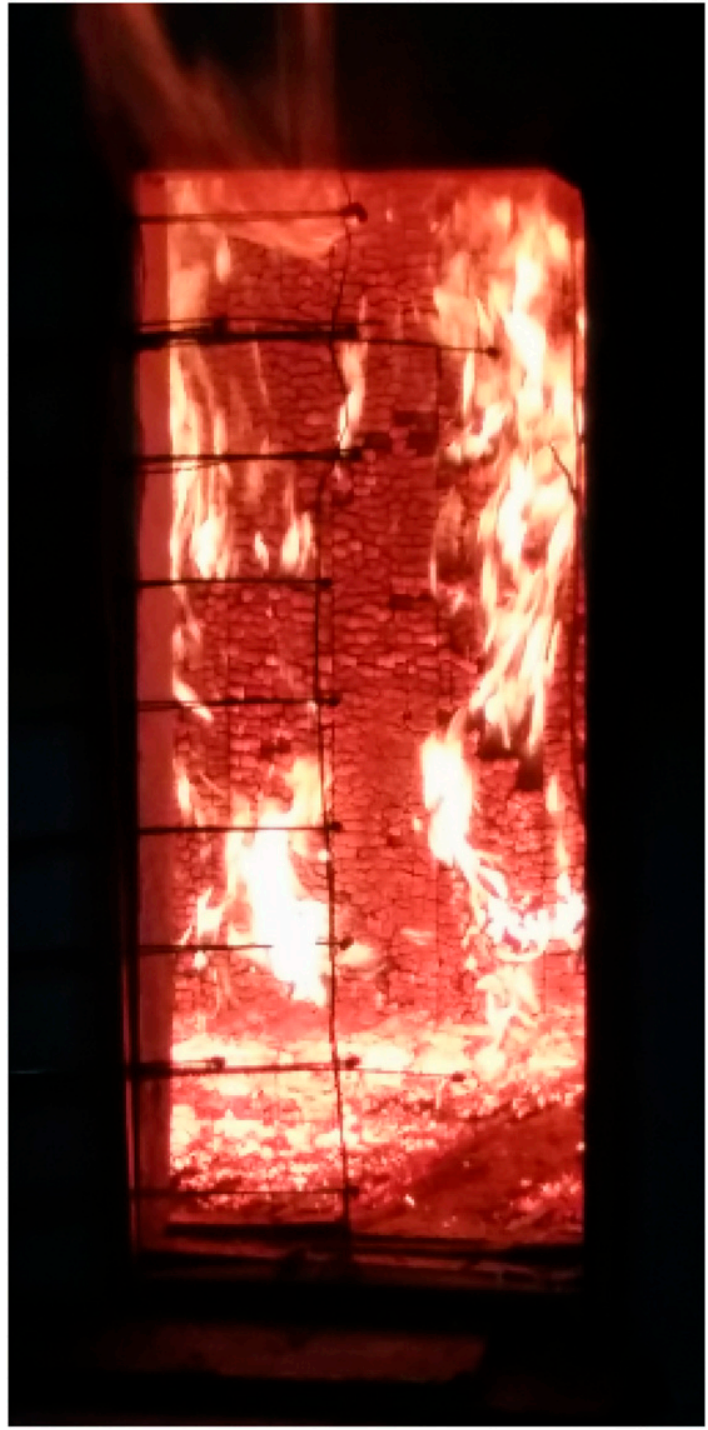

Figure 3. Cross-laminated timber with delamination occurring at ply interface (dark areas on wall) during fire test (image, Arup).

Two test compartments were constructed, each of 9.1-m long, 4.6-m wide, and $2.7 \mathrm{~m}$ high. Openings were a single door to the front, of $1.8-\mathrm{m} \times 2.0-\mathrm{m}$ wide opening (for four tests) and $3.6-\mathrm{m} \times 2.0-\mathrm{m}$ wide (for two tests). There were also two $150-\mathrm{mm}$ diameter openings at the rear to represent door leakage openings. There was a 20psf load on roof (approximately $1 \mathrm{kPa}$ ). Tests were instrumented by National Research Council,
Canada, with the tests carried out by NIST. The fuel load was identical for each test at $550 \mathrm{MJ} / \mathrm{m}^{2}$, with real furnishings. CLT panels were five-ply $175-\mathrm{mm}$ spruce-pine-fir CLT. CLT protection used multiple layers of $15.9-\mathrm{mm}$ (5/8 in.) thick Type X (fire-rated) gypsum board (plasterboard). Screw fixings were every $300 \mathrm{~mm}$. Test ignition was controlled and in the same rear location for each test.

The tests undertaken were

- Test 1: CLT was fully protected to all surfaces with three layers of Type X plasterboard and smaller wall opening.

- Test 2: CLT was fully protected to all surfaces with two layers of Type X plasterboard, with larger wall opening (see Fig 4).

- Test 3: The compartment had one long CLT wall exposed, with larger wall opening. The CLT protection was three layers on ceiling and two layers on walls.

- Test 4: The compartment had the CLT ceiling exposed, with smaller wall opening. The CLT protection was three layers.

- Test 5: The compartment had one long CLT wall exposed, with smaller wall opening. The CLT protection was three layers.

- Test 6: The compartment had one long CLT wall and the CLT ceiling exposed, with the smaller wall opening. CLT protection was three layers.

\section{Summary of FPRF Test Results}

Initial results from the FPRF CLT compartment tests have shown the following:

Test 1. Flashover occurred in $14.9 \mathrm{~min}$ and peak HRR was $9.5 \mathrm{MW}$. The test lasted more than $2 \mathrm{~h}$ and was terminated at $134 \mathrm{~min}$ after continuous fire decay with the HRR falling to $300 \mathrm{~kW}$. At the end of the test, two layers of plasterboard generally remained on the ceiling. The face layer of the plasterboard fell off the ceiling between 34 and $44 \mathrm{~min}$. All three layers of plasterboard were remaining on the walls at the end of the test. There was no significant charring to the CLT. 


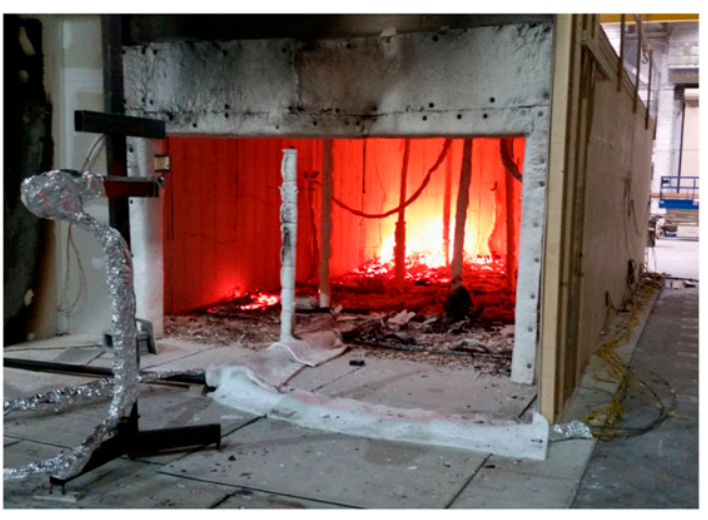

Figure 4. Fire Protection Research Foundation fire Test 2, near completion at $100 \mathrm{~min}$ after ignition (image, Arup).

Test 2. The compartment was fully protected to all surfaces with two layers of Type X plasterboard, with larger wall opening. Flashover occurred in 15.3 min with a peak HRR of 12.5 MW. This test had a larger opening and hence different HRR. The test was terminated at 104 min after continuous fire decay with the HRR falling less than $500 \mathrm{~kW}$.

Most of the base layer plasterboard remained on the ceiling whereas some pieces were lost in the middle section of the ceiling. The face layer of the plasterboard fell off the ceiling from 36 to $40 \mathrm{~min}$. All two layers of plasterboard remained on the walls at the end of the test. There was some evidence of charring on the ceiling.

Test 3. Flashover was reached about $14 \mathrm{~min}$ after ignition with an HRR of approximately 14.5 MW. Fire then stabilized at around $10 \mathrm{MW}$ for the next $26 \mathrm{~min}$. At approximately $70 \mathrm{~min}$ after flashover (around $84 \mathrm{~min}$ after ignition), the first lamination started to come away from the CLT. This resulted in a temporary increase in combustion on the exposed CLT wall, and a slight increase in HRR, from about 1.5 to $3 \mathrm{MW}$.

At approximately $95 \mathrm{~min}$ after flashover (109 min after ignition), the flaming on the exposed CLT wall had subsided and the HRR was back down to about $1.5 \mathrm{MW}$. At around $180 \mathrm{~min}$ after flashover (around $194 \mathrm{~min}$ after ignition), the second lamination started to come away and resulted in another temporary increase in combustion on the exposed CLT wall, and a slight increase in HRR, from about 0.7 to $1.7 \mathrm{MW}$. At approximately $4 \mathrm{~h}$ into the test, the HRR was down to around 0.8 MW. The test was terminated shortly after the 4-h mark (see Fig 5). The protected CLT walls all had evidence of charring after the test and up to 20-mm depth.

Test 4. Flashover was reached about $12 \mathrm{~min}$ after ignition and a peak HRR of 13.3 MW was reached. After flashover, the fully developed HRR stabilized around 7 to $8 \mathrm{MW}$ for the remainder of the fully developed phase. At around $40 \mathrm{~min}$ after flashover (around $52 \mathrm{~min}$ after ignition), the first CLT lamination on the exposed ceiling started to come away; however, there does not appear to be a significant increase in HRR.

A cooling phase started around $45 \mathrm{~min}$ after flashover (about $57 \mathrm{~min}$ after ignition). By around $75 \mathrm{~min}$ after flashover (87 min after ignition), the flaming on the exposed CLT ceiling had subsided and the HRR was just less than $2 \mathrm{MW}$. The HRR continued to decrease slowly for the next $50 \mathrm{~min}$, until reaching a low of about $0.9 \mathrm{MW}$ at around $125 \mathrm{~min}$ after flashover (about $137 \mathrm{~min}$ after ignition).

At approximately $135 \mathrm{~min}$ after flashover (approximately $147 \mathrm{~min}$ after ignition), the second

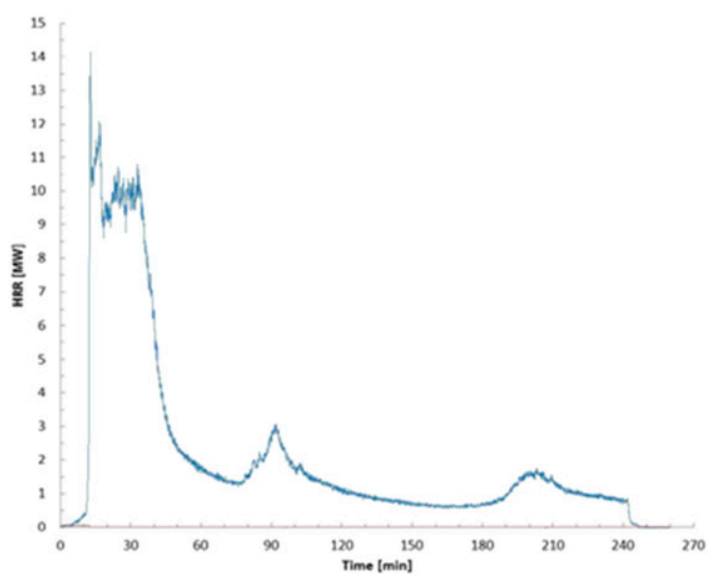

Figure 5. Heat release rate curve from Test 3 (preliminary only) (Kimball et al 2017). 
CLT lamination on the exposed ceiling started to delaminate. This resulted in an increase in combustion on the exposed CLT ceiling and an increase in HRR, from about 1 to 5 MW (see Fig 6). The test was terminated a few minutes after this increase in HRR, through hose streams applied to the fire. Although not entirely clear from the test, it appeared that the fire-rated protection of plasterboard stayed in place. There was some charring in limited areas behind the gypsum protection, once removed.

Test 5. Flashover occurred at approximately $18 \mathrm{~min}$, followed by a peak HRR of $9.5 \mathrm{MW}$. There was a period of decay to approximately 5.5-7 MW, at about 40-50 min after ignition. There was another peak to about $6.5 \mathrm{MW}$ after 50 min from ignition, assumed to be the outer ply delaminating. There was then a further steady slow decay to about $1 \mathrm{MW}$ at $100 \mathrm{~min}$ after ignition.

At around $2 \mathrm{~h}$ after ignition, the second ply started to delaminate and there was a regrowth in the HRR. This was quickly followed by gypsum protection falling off from the opposite wall, which resulted in more flame spread long the exposed wall. The HRR increased to approximately

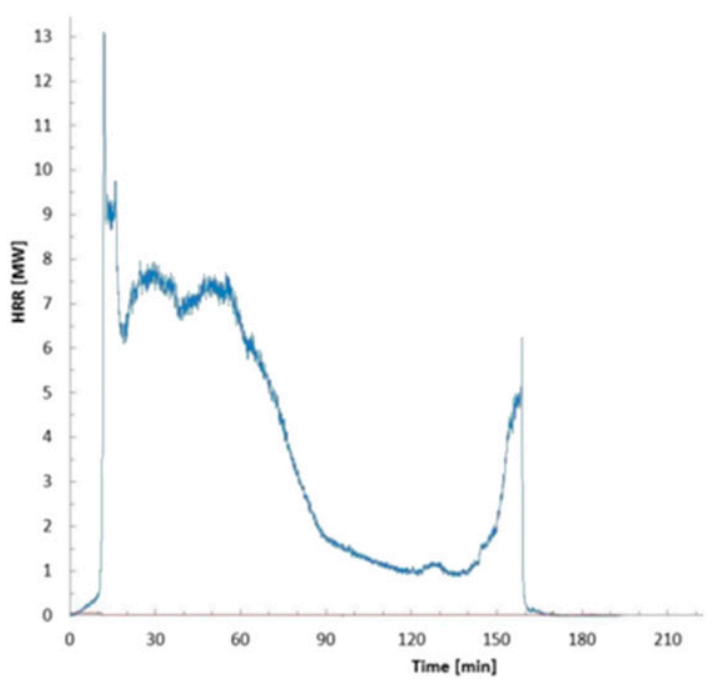

Figure 6. Heat release rate curve from Test 4 (preliminary only) (Kimball et al 2017).
$6 \mathrm{MW}$. There was a steady period of HRR for about $10 \mathrm{~min}$ and then large areas of gypsum started to fall from the ceiling, exposing more CLT. The HRR then accelerated up to approximately 9-10 MW. More gypsum was seen to fall from the walls and ceilings and it is assumed that most if not all of the gypsum had failed, exposing uncharred CLT. The peak HRR was still growing up past $10 \mathrm{MW}$ when the test was extinguished by hose streams at about $3 \mathrm{~h}$ into the test, given there was not going to be any decay before structure failure, given the large area of CLT that was exposed.

Test 6. Flashover occurred at approximately 16 min with a peak HRR of $13 \mathrm{MW}$. The HRR dropped back to $9 \mathrm{MW}$, then a period of steady burning between 7.5 and $10 \mathrm{MW}$. CLT protection was seen to fail from about 60 min into the test and continued to occur regularly through the test. Extinguishment by hose streams occurred at approximately $170 \mathrm{~min}$ into the test. Posttest, all walls were heavily charred and the exposed wall was charred through to the last ply. No plasterboard protection was visible.

\section{Discussion of Results from the Fire Testing}

The fire testing carried out has shown that the area and location of the exposed CLT surfaces impacts on the compartment fire. Of importance is whether the fire can decay through to self-extinguishment once all the moveable fuel (fixtures and fittings) have been consumed, allowing a compartment to withstand full burnout. If self-extinguishment does not occur, the combustible load-bearing structure is at risk in a fully developed fire scenario.

In reviewing the results of the FPRF tests, these are consistent in outcomes with other fire tests, where it has been shown that exposing large areas of mass timber can lead to sustained burning (as was observed in fire tests by McGregor [see Fig 7], Medina, Hox, and Hadden). For the compartment fire decay to self-extinguishment, once the combustible fuel of the furniture, fixtures, and contents within the compartment are consumed 
by the fire, the HRR needs to decay such that there is insufficient radiation to keep the exposed timber pyrolyzing. Timber will only ignite and burn when the heat flux received is greater than that of piloted ignition, being $12.5 \mathrm{~kW} / \mathrm{m}^{2}$ (Drysdale 2011).

Issues arise in compartment fires with exposed CLT that is susceptible to delamination, when the timber receives enough heat from the decaying fire, or the exposed timber surfaces reradiate to each other, such that burning through the ply causes delamination. The new timber (fuel) exposed to the heat of the fire produces an additional growth stage in the HRR and this regrowth may result in other consequences, such as CLT protection failure or a much prolonged fire duration. The interaction of compartment HRR, received heat flux, CLT susceptibility to delamination, and compartment ventilation are important in determining the compartment fire dynamics and whether self-extinguishment occurs.

From the reviewed fire tests, 20 have been carried out with some CLT exposed (four at Carleton University, five at the University of Edinburgh, five at TU Delft, one at SP, one at the University of Queensland, and four at NIST).

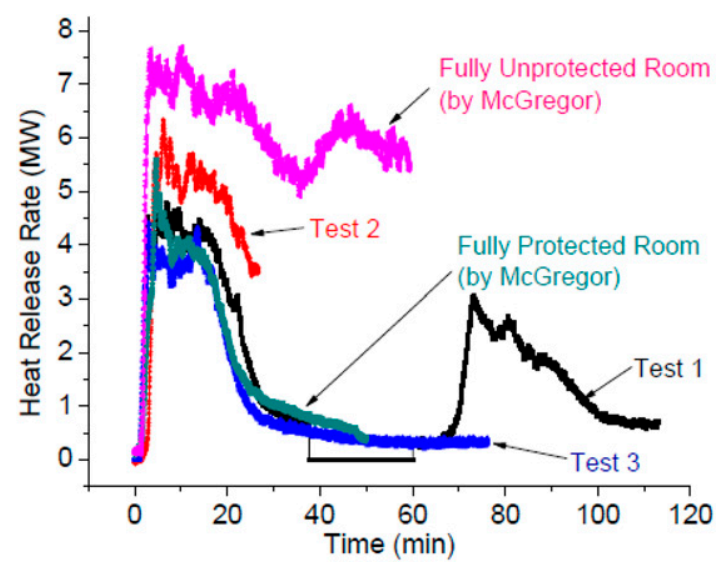

Figure 7. Results from Medina and McGregor, showing the difference in fire size (heat release rate) for a cross-laminated timber (CLT) room with full gypsum protection, one CLT wall exposed (Test 3), two walls exposed (Tests 1 and 2), and all walls exposed (Medina 2014).
In summary:

- Of the 20 tests on partially protected CLT compartments, 13 tests did not exhibit selfextinguishment (though some were related to protection failures) and in seven tests, the fire self-extinguished once all the movable or imposed fuel load was consumed.

- Where self-extinguishing behavior does not occur, the behavior is characterized by either continued burning (seven tests) or drop in HRR, followed by significant regrowth in HRR (six tests).

- In the seven tests where sustained burning occurred, multiple surfaces were exposed (three or more). There was an increase in HRR as the moveable fuel load was consumed, followed by a phase of steady HRR. The temperatures and radiation from burning surfaces within the compartment remain sufficiently high to sustain pyrolysis of the exposed timber until extinguishment by hose streams.

- In the six tests which exhibited HRR regrowth, at least two adjacent or opposing CLT surfaces were exposed, or there was a single surface and protection failure occurred to introduce multiple CLT surfaces. FPRF Test 4, with the ceiling exposed appears to be the only test where a single surface was exposed and significant regrowth occurred, with protection remaining intact. Delamination was observed before onset of HRR regrowth and the exposure of new timber is critical for the occurrence of the HRR regrowth.

- In the six tests where self-extinguishment occurred, three cases had a single exposed wall. With a single surface exposed, radiation from the protected surfaces and decaying compartmenting fire is insufficient to maintain pyrolysis of the exposed surface. Delamination has a lesser impact, and reliability of CLT protection is imperative. In the three further cases of self-extinguishment, two opposing or adjacent surfaces were exposed. The susceptibility of CLT delamination and received heat flux were critical in determining whether significant regrowth in HRR occurs in this configuration. 


\section{Implications of Fire Testing Results}

From the tests conducted to date, it is clear that a combination of exposed surface area, configuration (relative orientation of exposed surfaces), reliability of protection, compartment ventilation, and CLT delamination behavior are important parameters that influence whether compartment fire decay to self-extinguishment occurs or not. It should be noted that all tests investigated are unloaded and no authors comment on the potential effect of loaded walls and floors.

The impact for fire design on the structure and compartmentation to withstand burnout is as follows:

- There is a limited set of empirical evidence to support exposure of CLT and achieve compartment fire decay through to self-extinction.

- In designing structural fire protection to CLT elements, consideration of the consequences of failure of the protection components with respect to the decaying fire must be made.

- If the design is based on a structure surviving full burnout, then the area of exposed timber needs to be assessed relative to ventilation, with protection provided to prevent the timber-forming part of the fire load, for the full duration of the fire, through to selfextinguishment.

\section{SOLUTIONS FOR EXPOSED MASS TIMBER}

Given the need to understand exposed mass timber primary structure in high-rise buildings, models are being developed to assess the impact. The fire performance of exposed mass timber is not new, but with the introduction of CLT, existing models are being reworked. There is a limited area of exposed timber that is always going to be acceptable within a compartment, as it will not significantly impact the compartment fire. But there is also a limit to how much timber can be exposed before the mass timber significantly increases the HRR and duration of the fire. The delaminating behavior of CLT adds to the complexity. For design purposes, the maximum amount of energy released by the fully developed fire, including the exposed mass timber, cannot be permitted to result in failure of the constructed building elements.

The exposed mass timber as a fuel source can be accounted for by determining the timber charring as the char depth is a measure of how much mass has been converted and released as energy. Char depth is also a method of determining FRR for a loadbearing timber member (AWC 2015a). Where there are large areas of exposed mass timber and CLT, a constant char rate cannot be used, as charring varies with received heat flux, timber properties, compartment ventilation, fire growth, and decay through to extinguishment (Buchanan 2001; White 2016). The charring in the mass timber can be assessed using detailed computational fluid dynamics methods. This approach does require significant user input and computation time and has been shown to provide good accuracy where mass timber is limited in exposed area. Modeling of CLT delamination is still very difficult and should be approached with caution.

\section{Influence of CLT Delamination for Exposed Timber Surfaces}

The influence of CLT delamination on a compartment fire is a complex issue, with the resultant HRR difficult to predict. Where the CLT specified has been shown to be susceptible to delamination under fire conditions, then the area exposed will need to be very limited and potentially, fully protected. If the CLT being specified has been shown through fire testing to not delaminate and the charring is the same as for solid or glulam timber, then the exposed CLT area can be engineered, as the CLT behavior is predictable.

Given the desire by architects and building owners to have more timber exposed in their buildings, it is expected that future codes or manufacturing standards may require CLT to be produced to not delaminate (see Fig 8).

\section{SUMMARY}

High-rise buildings that are constructed with mass timber and CLT as the primary structure are 


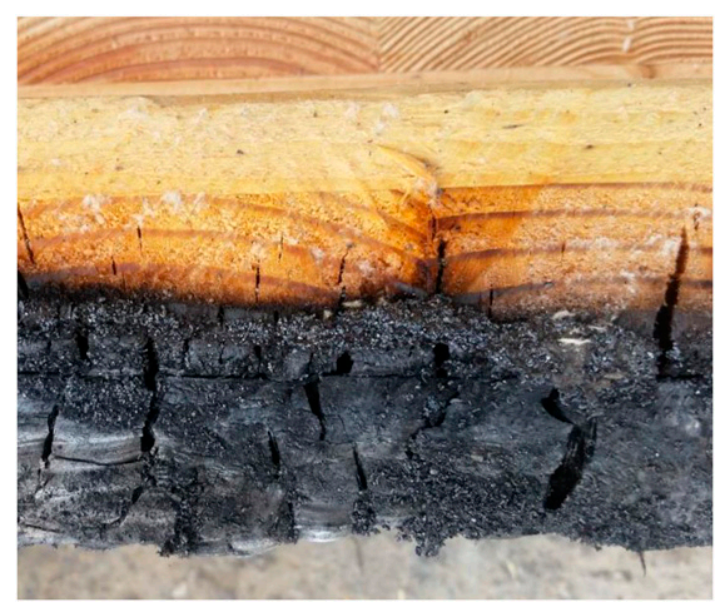

Figure 8. Cut section through five-ply cross-laminated timber floor panel, successfully passing a fire test to ASTM E119 to 2 h, without any delamination occurring (image, Arup).

being planned because of the sustainability benefits they offer, the increased speed of construction, and the potentially higher financial returns. The 2015 edition of the IBC allows lowand medium-rise buildings to have primary structural elements as exposed mass timber, with CLT. But once a building becomes a high rise, the building is required to meet a higher standard for fire protection and structural performance in fire.

Buildings designed with areas of exposed timber as part of the primary structure will have the compartment fire dynamics influenced by the additional fuel introduced. Exposed mass timber will increase the HRR if a fully developed fire can grow. If the area of exposed mass timber is not determined to be acceptable, then it could result in a fire that releases more energy than the primary structural elements can resist. Hence, exposed mass timber and CLT as part of the primary structural frame needs to be addressed conservatively and correctly to allow for its use.

\section{REFERENCES}

Aguanno M (2013) Fire resistance tests on cross-laminated timber floor panels: An experimental and numerical analysis. Department of Civil and Environmental Engineering, Carleton University, Ottawa, ON, Canada.
American Society for Testing and Materials (ASTM) (2015) ASTM E84: Standard test method for surface burning characteristics of building materials.

American Society for Testing and Materials (ASTM) (2016) ASTM E119: Standard test methods for fire tests of building construction and materials".

American Wood Council (AWC) (2012) Code conforming wood design. Leesburg, VA.

American Wood Council (AWC) (2015a) National design specification for wood construction. AWC, Leesburg, VA.

American Wood Council (AWC) (2015b) Calculating the fire resistance of exposed wood members, Technical report no. 10. AWC, Leesburg, VA.

Babrauskas V (2004) Wood char depth: Interpretation in fire investigations. In Presented at International Symposium on Fire Investigation, Fire Service College, Moreton-inMarsh, UK.

Barber D, Crielaard R, Li X (2016) Towards fire safe design of exposed timber in tall timber buildings. In Proc. World Conference of Timber Engineering, August 22-25, 2016, Vienna, Austria.

British Standards (2013) Eurocode 1: Actions on structures part 1-2: General actions-Actions on structures exposed to fire. BS EN 1991-1-2:2002, incorporating amendments to 2013 .

Buchanan A (2001) Structural design for fire safety. John Wiley and Sons.

City of New York (2014) 2014 construction codes. http:// www1.nyc.gov/site/buildings/codes/2014-constructioncodes.page.

Craft ST, et al (2011) Investigation of the behaviour of CLT panels exposed to fire. In Proc. 12th International Conference Fire and Materials.

Crielaard R (2015) Self-extinguishment of cross-laminated timber. Master's Thesis report, Faculty of Civil Engineering and Geosciences, Delft University of Technology.

Department of Commerce (1942) Building materials and structures, report BMS92, fire resistance classification of structures. National Bureau of Standards, report of sub-committee on fire resistance classifications of central housing committee on research, design and construction.

Drysdale D (2011) An introduction to fire dynamics, 3rd Ed. Wiley.

Emberley R, Gorska C, Bolanosa A, Lucherinia A, Solartea A, Soriguera D, Gutierrez M, Humphreys K, Hidalgoa J, Maluka C, Law A, Torero J (2017) Description of small and large-scale cross laminated timber fire tests. Fire Saf J 91:327-335.

Frangi A, et al (2008) Fire behaviour of cross-laminated solid timber panels. Institute of Structural Engineering, ETH Zurich, Zurich, Switzerland.

Hadden R, Bartlett A, Hidalgo J, Santamaria S, Wiesner F, Bisby L, Deeny S, Lane B (2017) Effects of exposed engineered timber on compartment fire dynamics. In Proc. 12th International Association of Fire Safety Science Symposium, June 10-16, 2017, Lund, Sweden. 
Hox K, et al (2015) "Branntest av massivtre" SP fire research, report A15101 (in Norwegian, translated by Arup).

International Code Council (ICC) (2015) International building code.

Kimball A, Hoehler M, Su J (2017) Fire safety challenges of tall wood-Report on cross laminated timber (CLT) compartment fire tests. In NFPA Conference and Expo, June 4-7, 2017, Boston, MA.

Karacabeyli E, Douglas B (2013) CLT handbook, US edition. FPInnovations SP529-E.

Klippel M, Schmid J, Frangi A (2016) Fire design of CLT, paper submitted for joint event of COST actions FP1402 and FP1404. KTH Stockholm.

McGregor C (2013) Contribution of cross laminated timber panels to room fires. Thesis, Department of Civil and Environmental Engineering, Carleton University, Ottawa, ON, Canada.

Medina A (2014) Fire resistance of partially protected crosslaminated timber rooms. Thesis, Faculty of Graduate and
Postdoctoral Affairs, Civil Engineering, Carleton University Ottawa, ON, Canada.

National Fire Protection Association (NFPA) (2015) "Life safety code" NFPA 101.

Reska P (2008) In-depth temperature profiles in pyrolyzing wood. Thesis submitted for the degree of Doctor of Philosophy, University of Edinburgh.

Underwriters Laboratories (2014) UL 263 - Standard for fire tests of building construction and materials.

United States Department of Agriculture (USDA) (2015) Tall wood building competition. https://www. rethinkwood.com/tall-wood-mass-timber/tall-woodcompetition.

Wilinder P (2010) Fire resistance in cross laminated timber. Master's thesis, Jönköping University, Jönköping, Sweden.

White R (2016) Analytical methods for determining fire resistance of timber members. In SFPE handbook of fire protection engineering, 5th Ed. 